\title{
O Plano e Programa ABC: uma análise da alocação dos recursos
}

\author{
The ABC Plan and Program: an evaluation of execution and distribution of \\ resources
}

\author{
Giovani William Gianetti ${ }^{1}$ (D), Joaquim Bento de Souza Ferreira Filho ${ }^{1}$ (D) \\ ${ }^{1}$ Escola Superior de Agricultura "Luiz de Queiroz" (ESALQ), Universidade de São Paulo (USP), Piracicaba (SP), Brasil. \\ E-mail: giovani.gianetti@usp.br; jbsferre@usp.br
}

Como citar: Gianetti, G. W., \& Ferreira Filho, J. B. S. (2021). O Plano e Programa ABC: uma análise da alocação dos
recursos. Revista de Economia e Sociologia Rural, 59(1), e216524. https://doi.org/10.1590/1806-9479.2021.216524

\begin{abstract}
Resumo: O presente estudo analisa regionalmente a alocação dos recursos para os diversos Sistemas de Produção Sustentáveis (SPS) do Programa ABC, a fim de subsidiar discussão a respeito da política expressa pelo Plano $\mathrm{ABC}$, relacionando as características econômicas, agropecuárias e ambientais. Foram utilizadas informaç̃̃es do Programa ABC de 2013 a 2017, variáveis de desempenho da agropecuária e classificação de aptidão agrícola (APT) predominante nos municípios para as análises e para a aplicação da correlação de Spearman. Quando comparados com os objetivos originais, os resultados mostram deficiências quanto à distribuição de recursos no âmbito das regiões brasileiras, dos subprogramas e da APT. Há concentração de $65 \%$ dos recursos nas regiões Centro-Oeste e Sudeste, $98 \%$ em quatro - de dez - dos SPS e $29 \%$ em municípios de alta APT. Nos municípios de alta APT, há ainda maior correlação do crédito com o desempenho econômico e agropecuário do que com a área de pastagens degradadas. Em geral, o rebanho bovino é a variável mais correlacionada com os empréstimos, com coeficiente de 0,53 em relação ao total de recursos. Alterações que contemplem diferenciação de incentivos conforme definições de áreas prioritárias e ampliação das ações de monitoramento são sugestões para aprimorar o Plano e Programa ABC.
\end{abstract}

Palavras-chave: agricultura de baixa emissão de carbono, crédito rural, políticas públicas.

\begin{abstract}
This study analyzes regionally the allocation of resources for the various Sustainable Production Systems (SPS) of the ABC Program, in order to support discussion about the policy expressed by the $A B C$ Plan, relating economic, agricultural and environmental characteristics. It was used the information from the ABC Program from 2013 to 2017, agricultural performance variables and the classification of predominant agricultural aptitude (APT) in the municipalities for the analysis and application of the Spearman correlation. When compared with the original objectives, the results show deficiencies in the distribution of resources within the Brazilian regions, subprograms and APT. There is a concentration of $65 \%$ of resources in the Midwest and Southeast, $98 \%$ in four (of ten) of SPS and 29\% in municipalities with high APT. In the municipalities with high APT there is an even greater correlation of credit with the economic and agricultural performance, than with the area of degraded pastures. In general, the cattle herd is the variable most correlated with the loans, with a coefficient of 0.53 in relation to total resources. Changes that include differentiation of incentives as defined priority areas and expansion of monitoring actions are suggestions to improve the ABC Plan and Program.
\end{abstract}

Keywords: low carbon agriculture, rural credit, public policies.

\section{Introdução}

No período de 1990 a 2012, o Brasil contribuiu em média com 4,68\% das emissões de Gases do Efeito Estufa (GEE) do mundo (Observatório do Clima, 2014), sendo a mudança do uso da terra e a agropecuária responsáveis por cerca de $80 \%$ das emissões de GEE $^{1}$ do Brasil, no período de 1990 a 2010 (Sistema de Registro Nacional de Emissões, 2018).

\footnotetext{
${ }^{1}$ Em dióxido de carbono equivalente ( $\left.\mathrm{CO}_{2} \mathrm{e}\right)$ em global warming potencial (GWP)
} 
A identificação de elevadas emissões de GEE no setor agropecuário incentivou a adoção voluntária de compromisso na $15^{\mathrm{a}}$ Conferência das Partes (COP-15) em 2009, para a redução de emissões de GEE entre $36,1 \%$ e $38,9 \%$ do projetado até 2020 . A Política Nacional de Mudança do Clima (PNMC) (Brasil, 2018), criada em 2009, originou o Plano Setorial de Mitigação e de Adaptação às Mudanças Climáticas para a Consolidação de uma Economia de Baixa Emissão de Carbono na Agricultura (Plano ABC), para atuação no período de 2010 a 2020. Os objetivos do Plano ABC estão direcionados para o desenvolvimento de ações para mitigação de emissões de GEE, bem como para melhoria da qualidade de solos, recuperação de áreas degradadas, redução do desmatamento, fixação de biomassa e tratamento de dejetos, realizadas através do incentivo à adoção de Sistemas de Produção Sustentáveis (SPS) na agropecuária. Para a execução do Plano $A B C$, elaborou-se o então Programa para a Redução da Emissão de Gases de Efeito Estufa na Agricultura (Programa ABC), um programa de crédito associado ao crédito rural, com taxas de juros subsidiadas (Brasil, 2012).

O compromisso firmado na COP-15 foi reforçado na COP-21, através da ratificação da pretendida Contribuição Nacionalmente Determinada (intended Nationally Determined Contribution - iNDC), visando reduzir as emissões de GEE do Brasil em 37\% e $43 \%$ em relação ao nível de emissões de 2005, devendo a primeira meta ser cumprida até 2025 e a segunda, até 2030. Para alcançar este objetivo, o país propôs realizar diversas ações, entre elas a intenção de ampliar e fortalecer o Plano $A B C$, com meta de recuperação adicional de 15 milhões de hectares com pastagens degradadas e implantação de mais 5 milhões de hectares em sistema de integração Lavoura-Pecuária-Floresta (iLPF) (Brasil, 2015).

Os objetivos expostos no Plano e Programa ABC, fortalecidos pela iNDC, de redução de emissões de GEE na ordem de 40\%, representam um desafio, principalmente, pois estudos já evidenciam as dificuldades em atingir os objetivos, como Ferreira Filho \& Horridge (2017). Os desafios do Plano e Programa ABC são exacerbados pelas dificuldades que podem surgir com a adoção de inovações tecnológicas e de manejo no meio rural. De acordo com Fornazier \& Vieira Filho (2012), o território nacional possui desigualdades de clima, qualidade de solos, adaptação de cultivos, arranjos produtivos, nível tecnológico, entre outros fatores, que resultam em divergência na distribuição de recursos produtivos e crescimento das regiões.

Embora o Plano $A B C$ possua características inovadoras em termos de execução (Programa $A B C$ ), existem poucas análises a respeito da sua efetividade, até o momento. Segundo o Observatório ABC (2017a), não existiam publicações oficiais públicas contemplando os resultados do Programa. Ainda conforme a Instituição, algumas evidências sugerem insuficiência na execução dos recursos do Programa $A B C$, principalmente quando comparadas as necessidades para cumprir metas previstas pelo Plano ABC. Também existem indícios sobre a heterogeneidade na alocação dos recursos entre regiões, estados e municípios (Assad, 2015).

O observatório $A B C$ realizou uma série de relatórios e pesquisas sobre a distribuição dos contratos do Programa ABC, a estrutura institucional, a abordagem ambiental e outros temas relacionados. O Observatório ABC (2017a) aponta que, desde o primeiro ano de vigência, os desembolsos se situaram em patamar inferior ao programado. Este estudo destaca que até a safra 2016/17, $\mathrm{R} \$ 23,45$ bilhões foram disponibilizados pelo governo, mas apenas $R \$ 15,64$ bilhões foram contratados, enquanto a meta de crédito concedido para 2020 é de $\mathrm{R} \$ 157$ bilhões. Ainda são citadas dificuldades burocráticas ao adquirir contratos do $A B C$, enquanto outras linhas de crédito rural são mais simples e rápidas. Os resultados reforçam a aderência desigual dentre os subprogramas, principalmente com o predomínio de contratos em Recuperação de Pastagens Degradas (RPD), bem como a concentração dos recursos no Centro-Sul do país.

De acordo com Assad (2015), existem carências na realização do Programa em relação a divulgação e disseminação das técnicas, afetando em grande escala as regiões Norte e Nordeste, e salientando, assim, a importância do fomento de ações de Assistência Técnica e Extensão Rural (ATER). Segundo o autor, também é necessária a implementação de ferramentas de monitoramento das mitigações de GEE e reajustes na taxa de juros, para tornar o Programa mais atrativo frente a outras opções do crédito rural.

Identificadas as deficiências do Plano e Programa ABC, o Observatório ABC (2015) realizou uma proposta de revisão com várias ações estruturais, de divulgação e capacitação, 
alterações institucionais e de governança, implantação de sistema de monitoração, incremento da transparência, entre outras ações. Destaca-se, dentre as propostas, a indicação da necessidade de priorizar os recursos de acordo com o potencial de mitigação de GEE.

Desta forma, este trabalho analisa regionalmente a alocação dos recursos para os diversos SPS do Programa $A B C$, a fim de subsidiar discussão a respeito da política de agricultura de baixa emissão de carbono, expressa pelo Plano $A B C$, relacionando as características econômicas, agropecuárias e ambientais. Além disso, a inclusão da variável de aptidão agrícola, que representa as condições edafoclimáticas dos municípios brasileiros, é uma contribuição original desta pesquisa e mostra-se importante para a discussão da priorização de recursos conforme os potencias de mitigação de GEE. Destaca-se ainda a utilização de informações provenientes do Ministério da Agricultura, Pecuária e Abastecimento (MAPA), não disponíveis para acesso aberto, que permitem classificar corretamente os subprogramas correspondentes às operações de crédito realizadas, pois os dados do Banco Central do Brasil (2018) apresentam, no período de 2013 a 2017, aproximadamente $\mathrm{R} \$ 7,3$ bilhões (em valores correntes) não classificados ("Sem Subprograma").

Além desta seção, o presente artigo é composto de outras quatro seções. A segunda seção apresenta a revisão de literatura, abordando o Plano e Programa ABC. A terceira seção é dedicada a detalhar os procedimentos metodológicos. A quarta seção apresenta os resultados e discussão, enquanto a última seção é dedicada às considerações finais.

\section{O Plano e o Programa ABC}

Derivado da Política Nacional sobre Mudança do Clima (PNMC), o Plano ABC (Brasil, 2012), criado de acordo com o artigo $3^{\circ}$ do Decreto 7.390/2010, tem vigência de 2010 até 2020. Este é o documento que fornece as diretrizes para a adoção de tecnologias sustentáveis para a produção agropecuária, de maneira a proporcionar o cumprimento do acordo voluntário de redução de emissões de Gases do Efeito Estufa (GEE) firmado na COP-15, em 2009. O Plano tem, como alguns de seus objetivos específicos, esforços para redução do desmatamento e para melhoria de aspectos sociais e da renda no meio rural, principalmente através das tecnologias de Recuperação de Pastagens Degradadas (RPD), Integração Lavoura-PecuáriaFloresta (iLPF) e Sistemas Agroflorestais (SAFs), Sistema Plantio Direto (SPD), Fixação Biológica do Nitrogênio (FBN), Florestas Plantadas (FLP), Tratamento de Dejetos Animais (TDA) e outras técnicas de adaptação às mudanças climáticas (Brasil, 2012).

Desta forma, o Plano ABC possui sete programas: RPD, iLPF, SPD, FBN, FLP, TDA e Adaptação às Mudanças Climáticas (AMC). Os subprogramas devem ser implementados para atingir as metas de recuperação de 15 milhões de hectares de pastagens degradadas (RPD), ampliação de quatro milhões de hectares de iLPF, expansão do SPD em oito milhões de hectares, substituição de fertilizantes nitrogenados em 5,5 milhões de hectares (FBN), plantio de três milhões de hectares de florestas (FLP) e o tratamento de 4,4 milhões de metros cúbicos de dejetos animais (TDA)².

As ações previstas para alcançar as metas do Plano abrangem atividades, como campanhas publicitárias, capacitação de técnicos e produtores rurais, transferência de tecnologia, regularização ambiental e fundiária, Assistência Técnica e Extensão Rural (ATER), estudos e planejamento, Pesquisa, Desenvolvimento \& Inovação (PD\&l), disponibilização de insumos, produção de sementes e mudas florestais, e, por fim, o crédito rural. Somando todas estas ações, a proposta inicial do Plano foi orçada em $R \$ 197$ bilhões.

O Programa $A B C^{3}$ é a linha de crédito rural destinada ao cumprimento do Plano $A B C$. $O$ crédito rural tem como objetivo fornecer ao setor rural, inclusive às indústrias de

\footnotetext{
${ }^{2}$ Cabe destacar que, de acordo com a proposta do Brasil (2015) ratificada em 2016 após a COP-21, a RPD deve ser acrescida de 15 milhões de hectares e a implantação de iLPF em cinco milhões de hectares, ambas as metas até 2030. Além disto, está prevista a restauração e o reflorestamento de 12 milhões de hectares até 2030.

${ }^{3}$ Ver Programa ABC (Banco Central do Brasil, 2016).
} 
beneficiamento, crédito para o custeio, o investimento ou a comercialização da produção, de maneira a fortalecer todo o setor, propiciando melhor uso da terra e geração de renda.

Este Programa é composto por nove subprogramas, definidos pela Resolução 4.105, art. $6^{\circ}$, e um subprograma regido pela Resolução 4.488 art. $4^{\circ}$ (ABC Bioma Amazônia). Destes subprogramas, sete atendem à proposta original ( $A B C$ Recuperação, $A B C$ Plantio Direto, $A B C$ Integração, $A B C$ Florestas, $A B C$ Ambiental, $A B C$ Tratamento de Dejetos, $A B C$ Fixação). Outros três subprogramas ( $A B C$ Orgânico, $A B C$ Dendê e $A B C$ Bioma Amazônia) foram criados especificamente a partir do Programa ABC (Observatório ABC, 2017a).

Observa-se que, apesar de o Plano ABC (Brasil, 2012) abordar indiretamente a capacidade dos Sistemas de Produção Sustentáveis (SPS) de ampliar a produtividade, ao mesmo tempo em que permitem alcançar as propostas ambientais, segundo o Observatório ABC (2017a), "Até o momento, não há nenhuma publicação oficial pública com estes resultados". Neste sentido, Barros (2017) evidencia que a definição do conceito e dos critérios para o estabelecimento de regiões prioritárias no Programa ABC é deficiente, determinando, através de entrevistas com o corpo técnico do Plano $A B C$, que o enfoque principal da política é a recuperação de pastagens degradadas. Segundo Dias Filho (2014), não existe metodologia definida para caracterizar pastagens degradadas, mas o autor indica que este fenômeno está diretamente relacionado a produtividade e qualidade das pastagens. Portanto, permite-se identificar regiões de baixa produtividade, principalmente na pecuária (pastagens degradadas e em más condições), como prioritárias ao Programa ABC, apresentando como principal indicador para esta caracterização a taxa de lotação de animais por hectare inferior a 0,7 (Barros, 2017).

Conforme mencionado anteriormente, a implementação do Plano ABC não depende exclusivamente dos recursos monetários. Outros recursos técnicos e humanos para a geração e difusão de conhecimento sobre os sistemas de produção sustentáveis, e ferramentas de gestão e monitoramento são necessários para alcançar os objetivos traçados. Quanto à geração de pesquisas relevantes para a introdução e evolução do Plano $A B C$ no território brasileiro, destacam-se as participações da Empresa Brasileira de Pesquisa Agropecuária (EMBRAPA), das Universidades e de outras entidades de pesquisa, como o Observatório ABC (Larcher, 2016). Estas pesquisas têm evidenciado particularidades na execução e distribuição dos recursos do Programa ABC.

Leal (2016) encontra elevada correlação em nível estadual entre os empréstimos do Programa $A B C$ e a produção agropecuária. No entanto, a correlação dos empréstimos com pastagens degradadas é baixa. Os resultados sugerem que o Programa ABC está sendo desenvolvido nos estados em que a agropecuária está previamente consolidada.

No sentido da caracterização das áreas prioritárias para o Programa ABC, Barros (2017) realizou uma classificação mesclando indicadores de qualidade das pastagens com o regime hídrico, o risco climático, a infraestrutura em transportes e a viabilidade econômica das culturas. O autor mostra que as áreas mais degradadas e de maiores necessidades ambientais possuem maiores deficiências econômicas e logísticas, indicando que ações para a viabilização de contratos com seguro rural poderiam ser realizadas para ampliar o interesse à contratação do Programa $A B C$.

Conforme o Observatório $A B C$ (2017b) o baixo volume de contratação dos recursos disponibilizados é um desafio. Segundo o estudo, se fossem realizados os investimentos nas áreas prioritárias, haveria um custo econômico de aproximadamente $\mathrm{R} \$ 3,70$ do consumo anual por habitante, enquanto que, se permitida a livre alocação, ocorreria um ganho de $\mathrm{R} \$ 41,18$. No entanto, os efeitos indiretos positivos sobre os recursos naturais e meio ambiente são maiores se consideradas as áreas prioritárias. Esta relação econômica exemplifica as dificuldades do Programa $A B C$ em atingir justamente as áreas de maior potencial de mitigação de GEE.

Como se pode verificar, na literatura citada, a relação dos empréstimos do $A B C$ com os fatores ambientais ou econômicos frequentemente é questionada, sendo este um dos aspectos centrais a serem avaliados neste estudo. 


\section{Metodologia e base de dados}

Neste estudo, utilizou-se o método da correlação de Spearman para relacionar a alocação do crédito do Programa ABC com outras variáveis, no nível municipal. A correlação é um indicador utilizado para verificar o relacionamento entre duas ou mais variáveis. Este indicador varia de $-1 \leq r \leq 1$, em que os extremos significam uma associação perfeita, inversa ou diretamente proporcional, e uma correlação igual a zero indica ausência de relação entre as variáveis (Chen \& Popovich, 2002).

O coeficiente de correlação mais conhecido é o de Pearson, que mensura a força de associação linear entre as variáveis. Se a relação entre as variáveis for não linear, o indicador de Pearson não apresentará uma medida correta da correlação. Neste caso, a correlação de Spearman avalia relações monótonas, sejam elas lineares ou não. O método de Spearman consiste na correlação dos postos ou ranks das variáveis, conforme a Equação 1. Vale ressaltar que a correlação de Spearman não representa causalidade, ou seja, apenas expressa uma associação entre o comportamento das variáveis (Chen \& Popovich, 2002).

$r_{s}=1-\frac{6 * \sum_{i=1}^{n} d_{i}^{2}}{n^{3}-n}$

Em que:

$r_{r}:$ Coeficiente de correlação de Spearman.

$d_{i}:$ posto $_{x i}-$ posto $_{y i}$ $n$ : número de variáveis.

Os dados utilizados neste estudo sobre o Programa $A B C$ são provenientes do Banco Central do Brasil (2018) através do Sistema de Operações do Crédito Rural e Proagro (SICOR) e da Matriz de Dados do Crédito Rural (MDCR), abrangendo de janeiro de 2013 a dezembro de 2017, e contêm informações sobre os subprogramas citados anteriormente. Adicionalmente, foi realizada adequada definição de subprograma dos contratos classificados como "Sem Subprograma" pelo Banco Central do Brasil (2018), através de informações suplementares fornecidas pelo Ministério da Agricultura, Pecuária e Abastecimento (MAPA). São aproximadamente $\mathrm{R} \$ 11,06$ bilhões de crédito e 42 mil contratos. Não foi possível, nesta etapa, organizar de forma padronizada os financiamentos realizados em datas anteriores à criação do SICOR, em 2013. Por limitações da base original, as áreas abrangidas pelos contratos não puderam ser analisadas.

Informações com discriminação municipal de área de pastagens, área de agricultura, área de pastagens degradadas, área de pastagens em más condições, rebanho animal, entre outros dados do meio rural, foram obtidas através do Censo Agropecuário de 2006 e 2017, realizado pelo Instituto Brasileiro de Geografia e Estatística (2018a), mesma fonte para os dados complementares provenientes da Produção Agrícola Municipal (PAM), da Pesquisa Pecuária Municipal (PPM) e da Produção da Extração Vegetal e da Silvicultura (PEVS) (Instituto Brasileiro de Geografia e Estatística, 2018b, 2018c, 2018d). Para verificar o desenvolvimento econômico, a variável de PIB municipal foi selecionada, incluindo os anos de 2013, 2014 e 2015, últimos dados disponíveis a partir do primeiro ano da base de dados sobre o Programa (Instituto Brasileiro de Geografia e Estatística, 2018e).

A variável de aptidão agrícola (APT) (Figura 1) representa uma análise inédita do potencial agrícola dos municípios em que estão sendo aplicados recursos do Programa ABC. Esta variável é utilizada como proxy do potencial de mitigação de emissões de GEE do Programa $A B C$ nos municípios. Neste sentido, espera-se que os municípios de baixa APT sejam prioritários aos investimentos do $A B C$, pois suas emissões de GEE por quantidade de produto devem ser maiores que nos demais, devido à existência de maiores áreas de baixa produtividade ou em cenário de degradação. A variável APT é definida como (Sparovek, 2015):

“(...) variável territorial complexa que integra aspectos ligados à fertilidade do solo, vocação climática e relevo (grifo nosso). Esta deve refletir as condições existentes para o cultivo sem irrigação de culturas anuais. A informação de Aptidão foi calculada em uma resolução espacial de 90 × 90 metros seguindo o máximo detalhamento de seu 
componente relevo. A Aptidão é calculada inicialmente como variável quantitativa contínua, que é posteriormente subdivida em categorias: Alta, Média, Baixa e Muito Baixa."

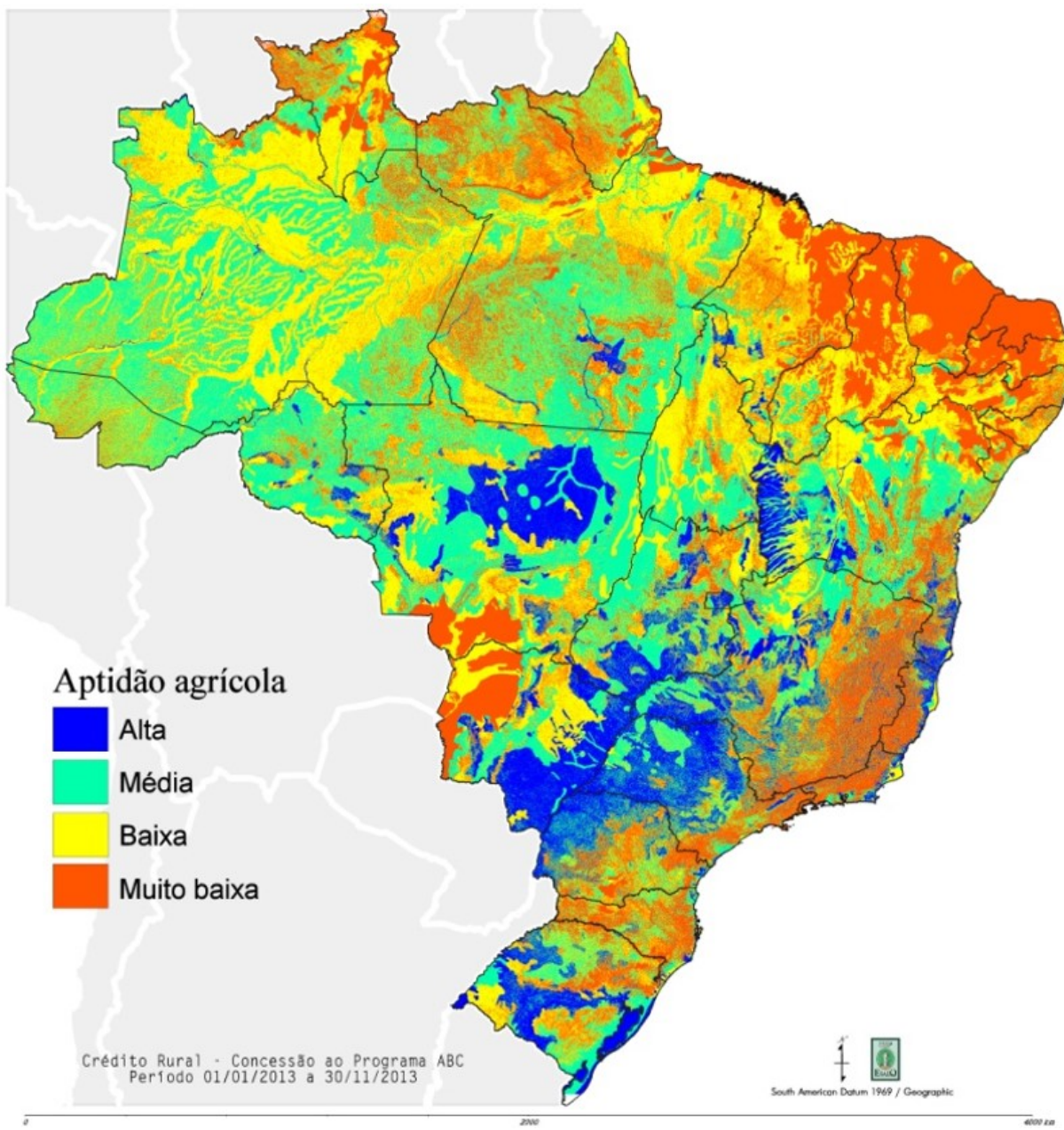

Figura 1. Classes de APT para o território brasileiro. Fonte: Sparovek (2015).

Realizou-se a classificação de aptidão agrícola (APT) agregada para os municípios, através da categoria com maior participação - predominante - na área do município. No presente estudo, os municípios foram agrupados em três categorias. Os municípios de predominância de alta aptidão (APT A), os de predominância de média aptidão (APT B) e os municípios de baixa e muito baixa aptidão (APT CD).

Após a construção da base de dados, algumas operações foram realizadas. Municípios sem caracterização de aptidão agrícola (APT) foram excluídos, representando uma redução de cerca de 1,63\% do crédito total. Para a apresentação das estatísticas descritivas, houve ainda a inclusão dos subprogramas de menor expressão em um único grupo (OUT).

Para a análise através da correlação de Spearman, utilizou-se a soma dos valores de crédito e das variáveis selecionadas para todo o período de análise, exceto para pastagens degradadas. As informações sobre pastagens degradadas estão disponíveis apenas para 2006 e, para pastagens em más condições, para 2017 (Instituto Brasileiro de Geografia e Estatística, 2018a). Foi realizada a correlação por pares (pairwise), que considera as informações disponíveis para cada par de variáveis ${ }^{4}$.

${ }^{4}$ Este procedimento gerou número de observações heterogêneo para cada variável em razão da diferente disponibilidade de informações entre os municípios. 


\section{Resultados e Discussão}

Verificam-se a partir da Tabela 1 o crédito concedido e os contratos por subprogramas, regiões e aptidão agrícola, em relação ao total do Brasil. Observa-se que os subprogramas de RPD, SPD, FLP e iLPF somam cerca de $98,2 \%$ do crédito concedido e $99,0 \%$ das observações. Existe predominância da atividade de Recuperação de Pastagens Degradadas em relação às demais linhas do Programa ABC.

Através das informações dos empréstimos concedidos, verifica-se que os Programas $A B C$ Orgânico, $A B C$ Ambiental ( $A M C$ ), $A B C$ Tratamento de Dejetos (TDA), $A B C$ Dendê, $A B C$ Fixação (FBN) e $A B C$ Bioma Amazônia possuem ínfimo volume de contratos. Os Programas $A B C$ Orgânico, $A B C$ Dendê e $A B C$ Bioma Amazônia apresentam maiores desafios para análise de suas deficiências, pois, como mencionado anteriormente, não foram definidos no Plano ABC.

De acordo com Hungria et al. (2013), a aplicação de fixação biológica de nitrogênio é lucrativa e a implantação apenas nas culturas de feijão e soja seria suficiente para cumprir as metas do Plano ABC quanto a este sistema de produção. No entanto, observou-se baixo desempenho desta alínea de crédito. Os autores indicam o pouco interesse pelos produtores em adquirir os contratos especificamente de FBN em razão do baixo custo desta tecnologia. Dados da Empresa Brasileira de Pesquisa Agropecuária (2017) mostram que o custo de inoculação de tratamento para fixação biológica de nitrogênio na cultura de soja era de aproximadamente $\mathrm{R} \$ 8,00$ por hectare, valor suficientemente baixo para corroborar a hipótese da inexistência de necessidade de contratação do Programa ABC para esta finalidade.

Quanto ao subprograma de TDA, a especificidade técnica e a necessidade de capital são algumas das hipóteses para a pequena representatividade deste subprograma. Segundo Kunz et al. (2005), os custos da implementação de sistemas de TDA em criação de suínos são elevados em comparação à capacidade de investimento do produtor.

A proposta para adequação às mudanças climáticas (AMC), visando principalmente recuperar Áreas de Preservação Permanente (APPs) e Reserva Legal (RL), pode não ser atrativa para os produtores rurais. De acordo com Sparovek et al. (2011), a não conformidade das áreas de RL e APP envolve a grande periodicidade de alterações na legislação, a deficiência na fiscalização e a não aceitação das regras pelos produtores.

Tabela 1. Crédito concedido e contratos por subprogramas, regiões e aptidão agrícola, em relação ao total do Brasil

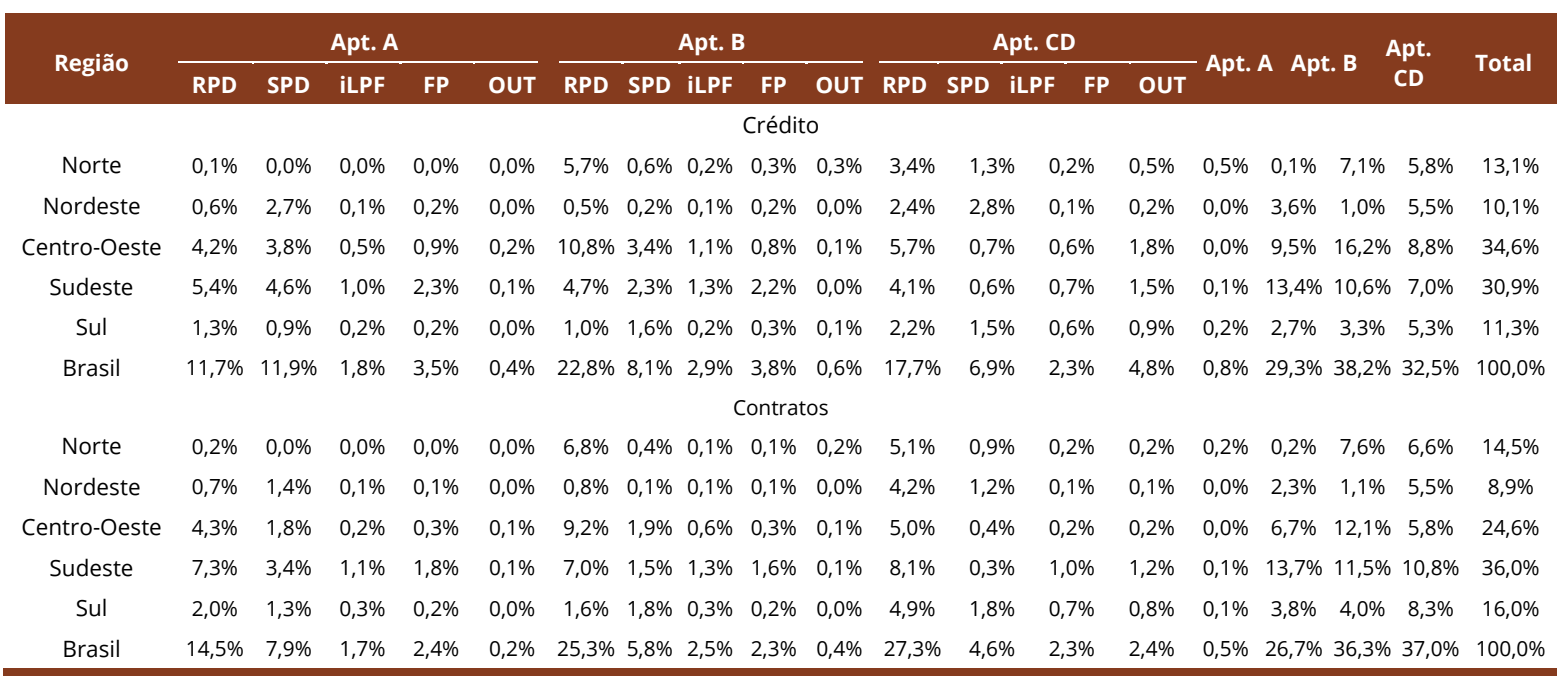

Fonte: Resultados da pesquisa. Apt. A: municípios de alta aptidão agrícola; Apt. B: municípios de média aptidão agrícola; Apt. CD: municípios de baixa e muito baixa aptidão agrícola.

Além da concentração encontrada nas linhas de financiamento do Programa, existe a concentração de recursos em grupos de estados e regiões brasileiras. As regiões Centro-Oeste e Sudeste receberam cerca de $65,5 \%$ dos recursos. Para as regiões Norte e Nordeste, 
destinaram-se aproximadamente 23,2\% dos empréstimos. De acordo com Assad (2015), estas duas últimas regiões deveriam ser priorizadas no Plano $A B C$.

Como mencionado anteriormente, os municípios de predominância de baixa APT são referidos como prioritários no sentido de mitigação de GEE. No entanto, também são os locais onde a recuperação da pastagem e/ou solos seria mais custosa e difícil. Como há menor aptidão para agropecuária nestes locais, espera-se que existam áreas em cenários de degradação mais intensos, exigindo maior quantidade de insumos para recuperação. Além das condições edafoclimáticas, também existem aspectos econômicos que podem apresentar maiores entraves, principalmente nos municípios localizados nas regiões Norte e Nordeste, como argumentado por Barros (2017). Neste sentido, observa-se que apenas as regiões Nordeste e Sul possuem os municípios de baixa APT como principal destino dos recursos. Nas regiões Norte e Centro-Oeste, há maior alocação de recursos em municípios de predominância da média APT. Na região Sudeste, os recursos foram destinados inversamente ao esperado, ou seja, maior parcela destinou-se para municípios caracterizados pela alta APT.

As regiões Norte e Nordeste são apontadas como as de maiores necessidades de investimentos do ABC (Assad, 2015). Pode-se ainda destacar que possuem elevada concentração de áreas de baixa e muito baixa APT (Figura 1), mas são as que menos recebem recursos. Além disso, apesar de a região Nordeste apresentar os municípios de baixa APT como principal destino de recursos, cerca de 35\% do crédito do Programa ABC desta região foi aplicado em municípios de alta APT. Para que os investimentos sejam realizados nas regiões de baixa APT, devem existir condições diferenciadas, como, por exemplo, maiores subsídios de taxas de juros e associação do crédito com a ATER pública.

Ocorreu maior contratação do Programa ABC em municípios de predominância de alta e média APT, que geralmente possuem maior nível técnico e de produtividade. Neste sentido, a linha de crédito do $A B C$ funciona como qualquer outro mecanismo do crédito rural. No entanto, não se pode desconsiderar a vantagem do crédito do $A B C$ de estimular, mesmo em regiões já produtivas, a adoção de Sistemas de Produção Sustentáveis (SPS). Os recursos destinados aos municípios de predominância de média APT poderiam ser justificados, identificando estes como intermediários entre os desafios para a correção da degradação do solo e pastagens e os benefícios potenciais de mitigação de emissões de GEE. Se analisados somente os esforços realizados nas regiões de baixa APT, a abrangência do Programa é diminuta. Destaca-se que a proposta do Plano ABC está em recuperar pastagens e áreas degradadas, e implementar Sistemas de Manejo Sustentáveis para mitigar a emissão de GEE. Para isto, será necessário recuperar justamente as regiões em que a degradação é mais extrema e a agropecuária é menos produtiva.

A discussão anteriormente apresentada evidencia a relação entre o custo de implantação dos SPS, os benefícios econômicos e o potencial de mitigação de GEE, conforme as diferentes condições de APT. Somente através dos cálculos de indicadores de rentabilidade e razão do coeficiente de mitigação de GEE (por unidade de produto) pelos investimentos necessários à implantação dos SPS, considerando as divergências de APT, que seria possível analisar esta relação. Ou seja, calcular qual o melhor retorno de mitigação de emissões de GEE por unidade monetária investida. Por isto, conforme apresentado na metodologia, considerou-se, por hipótese, a prioridade de alocação de recursos em municípios de baixa APT, analisando principalmente o maior potencial de mitigação de GEE. 
Tabela 2. Crédito concedido em atividade agrícola e pecuária por subprogramas, regiões e APT, em relação ao total do Brasil, em porcentagem (\%)

\begin{tabular}{|c|c|c|c|c|c|c|c|c|c|c|c|c|c|c|c|c|c|c|c|}
\hline \multirow{2}{*}{ Região } & \multicolumn{6}{|c|}{ Apt. A } & \multicolumn{4}{|c|}{ Apt. B } & \multicolumn{5}{|c|}{ Apt. CD } & \multirow{2}{*}{$\begin{array}{c}\text { Apt. } \\
\text { A }\end{array}$} & \multirow{2}{*}{$\begin{array}{c}\text { Apt. } \\
\text { B }\end{array}$} & \multirow{2}{*}{$\begin{array}{l}\text { Apt. } \\
\text { CD }\end{array}$} & \multirow{2}{*}{ Total } \\
\hline & RPD & SPD & iLPF & FP & OUT & RPD & SPD & iLPF & FP & OUT & RPD & SPD & iLPF & FP & OUT & & & & \\
\hline \multicolumn{20}{|c|}{ Agrícola } \\
\hline Norte & $0,0 \%$ & $0,0 \%$ & $0,0 \%$ & $0,0 \%$ & $0,0 \%$ & $0,2 \%$ & $0,6 \%$ & $0,1 \%$ & $0,3 \%$ & $0,0 \%$ & $0,1 \%$ & $1,3 \%$ & $0,1 \%$ & $0,4 \%$ & $0,1 \%$ & $0,0 \%$ & $1,3 \%$ & $2,0 \%$ & $3,3 \%$ \\
\hline Nordeste & $0,1 \%$ & $2,7 \%$ & $0,1 \%$ & $0,1 \%$ & $0,0 \%$ & $0,0 \%$ & $0,2 \%$ & $0,1 \%$ & $0,1 \%$ & $0,0 \%$ & $0,0 \%$ & $2,8 \%$ & $0,1 \%$ & $0,2 \%$ & $0,0 \%$ & $3,1 \%$ & $0,4 \%$ & $3,1 \%$ & $6,6 \%$ \\
\hline $\begin{array}{l}\text { Centro- } \\
\text { Oeste }\end{array}$ & $0,5 \%$ & $3,6 \%$ & $0,4 \%$ & $0,8 \%$ & $0,2 \%$ & $0,5 \%$ & $3,4 \%$ & $0,8 \%$ & $0,7 \%$ & $0,1 \%$ & $0,4 \%$ & $0,6 \%$ & $0,5 \%$ & $1,7 \%$ & $0,0 \%$ & $5,5 \%$ & $5,5 \%$ & $3,2 \%$ & $14,2 \%$ \\
\hline Sudeste & $2,2 \%$ & $4,5 \%$ & $1,0 \%$ & $2,2 \%$ & $0,0 \%$ & $0,8 \%$ & $2,2 \%$ & $1,2 \%$ & $2,2 \%$ & $0,0 \%$ & $0,1 \%$ & $0,6 \%$ & $0,7 \%$ & $1,4 \%$ & $0,0 \%$ & $10,0 \%$ & $6,4 \%$ & $2,9 \%$ & $19,3 \%$ \\
\hline Sul & $0,2 \%$ & $0,9 \%$ & $0,0 \%$ & $0,2 \%$ & $0,0 \%$ & $0,3 \%$ & $1,6 \%$ & $0,1 \%$ & $0,3 \%$ & $0,1 \%$ & $0,2 \%$ & $1,4 \%$ & $0,3 \%$ & $0,9 \%$ & $0,1 \%$ & $1,3 \%$ & $2,5 \%$ & $2,9 \%$ & $6,7 \%$ \\
\hline Brasil & $2,9 \%$ & $11,7 \%$ & $1,5 \%$ & $3,4 \%$ & $0,3 \%$ & $1,8 \%$ & $8,0 \%$ & $2,4 \%$ & $3,7 \%$ & $0,2 \%$ & $0,8 \%$ & $6,7 \%$ & $1,7 \%$ & $4,7 \%$ & $0,2 \%$ & $19,8 \%$ & $16,1 \%$ & $14,2 \%$ & $50,0 \%$ \\
\hline \multicolumn{20}{|c|}{ Pecuária } \\
\hline Norte & $0,1 \%$ & $0,0 \%$ & $0,0 \%$ & $0,0 \%$ & $0,0 \%$ & $5,5 \%$ & $0,0 \%$ & $0,1 \%$ & $0,0 \%$ & $0,3 \%$ & $3,3 \%$ & $0,0 \%$ & $0,1 \%$ & $0,0 \%$ & $0,4 \%$ & $0,1 \%$ & $5,9 \%$ & $3,8 \%$ & $9,8 \%$ \\
\hline Nordeste & $0,5 \%$ & $0,0 \%$ & $0,0 \%$ & $0,0 \%$ & $0,0 \%$ & $0,5 \%$ & $0,0 \%$ & $0,0 \%$ & $0,0 \%$ & $0,0 \%$ & $2,3 \%$ & $0,0 \%$ & $0,0 \%$ & $0,0 \%$ & $0,0 \%$ & $0,6 \%$ & $0,5 \%$ & $2,4 \%$ & $3,5 \%$ \\
\hline $\begin{array}{l}\text { Centro- } \\
\text { Oeste }\end{array}$ & $3,7 \%$ & $0,2 \%$ & $0,1 \%$ & $0,1 \%$ & $0,0 \%$ & $10,3 \%$ & $0,0 \%$ & $0,3 \%$ & $0,1 \%$ & $0,0 \%$ & $5,3 \%$ & $0,1 \%$ & $0,2 \%$ & $0,1 \%$ & $0,0 \%$ & $4,1 \%$ & $10,7 \%$ & $5,6 \%$ & $20,4 \%$ \\
\hline Sudeste & $3,2 \%$ & $0,1 \%$ & $0,1 \%$ & $0,0 \%$ & $0,0 \%$ & $4,0 \%$ & $0,0 \%$ & $0,0 \%$ & $0,0 \%$ & $0,0 \%$ & $4,0 \%$ & $0,0 \%$ & $0,0 \%$ & $0,0 \%$ & $0,1 \%$ & $3,4 \%$ & $4,1 \%$ & $4,1 \%$ & $11,7 \%$ \\
\hline Sul & $1,2 \%$ & $0,0 \%$ & $0,1 \%$ & $0,0 \%$ & $0,0 \%$ & $0,7 \%$ & $0,0 \%$ & $0,1 \%$ & $0,0 \%$ & $0,0 \%$ & $2,0 \%$ & $0,1 \%$ & $0,3 \%$ & $0,0 \%$ & $0,1 \%$ & $1,4 \%$ & $0,8 \%$ & $2,4 \%$ & $4,6 \%$ \\
\hline Brasil & $8,7 \%$ & $0,2 \%$ & $0,3 \%$ & $0,1 \%$ & $0,1 \%$ & $20,9 \%$ & $0,2 \%$ & $0,5 \%$ & $0,2 \%$ & $0,4 \%$ & $16,9 \%$ & $0,2 \%$ & $0,6 \%$ & $0,1 \%$ & $0,6 \%$ & $9,5 \%$ & $22,1 \%$ & $18,4 \%$ & $50,0 \%$ \\
\hline
\end{tabular}

Fonte: Resultados da pesquisa. Apt. A: municípios de alta aptidão agrícola; Apt. B: municípios de média aptidão agrícola; Apt. CD: municípios de baixa e muito baixa aptidão agrícola.

É importante destacar uma análise relacionada às emissões de GEE por unidade de produto, pois, considerando os valores absolutos, a ampliação, por exemplo, do número de animais por unidade de área pode resultar em crescimento de emissões de GEE, ainda que o volume de emissões por quilo de carne produzida tenha decrescido.

O percentual do crédito total alocado nas atividades, agrícola e pecuária, é apresentado na Tabela 2. Quanto à agricultura, observa-se que os municípios de APT mais elevadas recebem maiores parcelas de recursos. Apenas nas regiões Norte e Sul, o crédito agrícola em municípios de baixa APT foi predominante. No entanto, a representatividade destas regiões no total empregado pelo Programa ABC é baixa.

$\mathrm{Na}$ atividade da pecuária (Tabela 2), a maior participação no crédito é de municípios de média APT. Apenas nas regiões Nordeste e Sul, os municípios de baixa APT possuem maior participação no volume de crédito. No entanto, são também as duas menores regiões no total de crédito à pecuária.

Nos empréstimos à atividade pecuária, a priorização dos investimentos foi mais coerente com os objetivos do $A B C$, comparada à observada na agricultura, devido à maior quantidade de recursos de crédito destinados aos municípios de aptidão mais baixa. Ainda assim, cerca de $9,5 \%$ do crédito total do Programa $A B C$ destinado à pecuária foi aplicado em municípios de alta APT.

A Tabela 3 apresenta os coeficientes de correlação obtidos entre os empréstimos totais e as variáveis selecionadas. Observa-se que a correlação dos investimentos do ABC com a quantidade de pastagens degradadas e em más condições é positiva, acentuando-se quando os recursos são destinados aos municípios de baixa APT. A correlação do Programa ABC com a produção de lavouras temporárias e com o PIB municipal também é positiva, mas amplia-se nos municípios de APT mais elevada. Portanto, há um contraste: municípios de baixa APT apresentam maiores coeficientes de correlação entre o volume de crédito e a baixa qualidade das pastagens, ao mesmo tempo em que há menores correlações entre este volume e indicadores de desempenho econômico, quando comparados aos municípios de alta APT.

As correlações do PIB municipal (2013, 2014 e 2015) com as pastagens degradadas para o Crédito Total do Programa ABC foram significativas no nível de $1 \%$, em todos as classificações de APT, em que se registraram correlações positivas, mas mais fracas que as apresentadas entre as variáveis de PIB municipal e o crédito do Programa ABC. As correlações das variáveis de PIB municipal com as pastagens em más condições para o Crédito Total do Programa $A B C$ apresentaram significância estatística no nível de $1 \%$ apenas para os municípios de alta APT, observando-se que o coeficiente foi positivo, mas menor que o 
observado entre o PIB municipal e o crédito do Programa ABC. Assim, a associação do PIB e empréstimos do $A B C$ é mais forte que a associação do PIB e pastagens degradadas ou em más condições 5 .

Tabela 3. Correlação de Spearman do Programa ABC com variáveis selecionadas, por aptidão agrícola e atividade econômica

\begin{tabular}{|c|c|c|c|c|c|c|c|c|c|c|c|c|}
\hline \multirow{2}{*}{$\begin{array}{c}\text { Correlação } \\
\text { de }\end{array}$} & \multicolumn{4}{|c|}{ Crédito Total } & \multicolumn{4}{|c|}{ Crédito Agrícola } & \multicolumn{4}{|c|}{ Crédito Pecuária } \\
\hline & Apt. A & Apt. B & Apt. CD & Total & Apt. A & Apt. B & Apt. CD & Total & Apt. A & Apt. B & Apt. CD & Total \\
\hline $\begin{array}{l}\text { Pastagem } \\
\text { Degradada } \\
2006\end{array}$ & $0,3656^{*}$ & $0,5134^{*}$ & $0,5178^{*}$ & $0,4587 *$ & $0,1784^{*}$ & $0,3496 *$ & $0,4292^{*}$ & 0,3181 * & $0,5107 *$ & $0,5520 *$ & $0,5122^{*}$ & $0,5224^{*}$ \\
\hline $\begin{array}{l}\text { Pastagem } \\
\text { em Más } \\
\text { Condições } \\
2017\end{array}$ & $0,3935 *$ & $0,4723 *$ & $0,4975 *$ & $0,4029 *$ & $0,1989 *$ & $0,3388^{*}$ & $0,4564^{*}$ & 0,2981 * & $0,5006^{*}$ & $0,5352^{*}$ & 0,5001 * & $0,4814^{*}$ \\
\hline $\begin{array}{c}\text { Rebanho } \\
\text { Bovino }\end{array}$ & $0,4638 *$ & $0,6019 *$ & $0,5575 *$ & $0,5332 *$ & $0,2352^{*}$ & 0,3641 * & $0,3562^{*}$ & $0,3168 *$ & $0,6355^{*}$ & $0,6960 *$ & $0,6023^{*}$ & 0,6401 * \\
\hline $\begin{array}{l}\text { Rebanho } \\
\text { Suíno }\end{array}$ & $0,2683^{*}$ & $0,2193^{*}$ & $0,0514 * * *$ & $0,1226^{*}$ & $0,1798^{*}$ & $0,1621 *$ & $-0,0829^{\star \star}$ & 0,0323 & $0,2787^{\star}$ & $0,2358^{*}$ & $0,1338^{*}$ & $0,1952^{*}$ \\
\hline $\begin{array}{l}\text { Rebanho de } \\
\text { Galináceos }\end{array}$ & 0,0587 & 0,0116 & $0,0177 * * *$ & 0,0373 ** & 0,0394 & 0,0127 & $-0,0649^{* * *}$ & $-0,0025$ & 0,0592 & $-0,0285$ & 0,0457 & 0,0323 \\
\hline $\begin{array}{l}\text { Lavouras } \\
\text { Temporárias }\end{array}$ & $0,4092 *$ & $0,2520^{*}$ & $0,2190 *$ & $0,3202 *$ & $0,4624^{*}$ & 0,3391 * & $0,2773^{*}$ & $0,3850 *$ & $0,0891 * * *$ & 0,0571 & $0,1756^{*}$ & $0,1550 *$ \\
\hline $\begin{array}{l}\text { Cana-de- } \\
\text { açúcar }\end{array}$ & $0,3020 *$ & $-0,0367$ & $-0,0086$ & $0,1146 *$ & $0,3927 *$ & 0,0305 & $-0,0121$ & $0,1825^{*}$ & $-0,0350$ & $-0,1906^{*}$ & $-0,0215$ & $-0,0517 * *$ \\
\hline $\begin{array}{c}\text { Milho } \\
\text { (em grão) }\end{array}$ & 0,1701 * & $0,2185^{*}$ & $0,1216^{*}$ & $0,1853^{*}$ & $0,2077^{*}$ & $0,1965 *$ & $0,1656^{*}$ & $0,1864^{*}$ & 0,0499 & $0,1282^{*}$ & $0,0665^{\star \star}$ & 0,1101 * \\
\hline $\begin{array}{c}\text { Soja } \\
\text { (em grão) }\end{array}$ & $0,1997 *$ & $0,2650^{*}$ & $0,2715^{*}$ & $0,2885^{*}$ & $0,1863^{*}$ & $0,2554^{*}$ & $0,2912^{*}$ & $0,2603^{*}$ & $0,1369 *$ & 0,1821 * & $0,2392 *$ & 0,2241 * \\
\hline $\begin{array}{l}\text { Lavouras } \\
\text { Permanente } \\
\mathrm{s}\end{array}$ & 0,1241 * & $-0,0789 * *$ & $-0,0739 * *$ & 0,0104 & $0,1009 * *$ & 0,0480 & $-0,0838 * *$ & 0,0329 & $-0,0529$ & $-0,1816^{*}$ & $-0,1017^{*}$ & $-0,0805^{*}$ \\
\hline $\begin{array}{l}\text { Cacau (em } \\
\text { amêndoa) }\end{array}$ & $0,1095^{\star \star}$ & $0,0894 * *$ & 0,0239 & 0,0470 ** & 0,0633 & 0,0102 & $-0,0321$ & $-0,0065$ & $0,1154^{* *}$ & $0,1532^{*}$ & $0,0899 *$ & $0,1126^{*}$ \\
\hline $\begin{array}{c}\text { Café } \\
\text { (em grão) }\end{array}$ & 0,0364 & $-0,0889 * *$ & $-0,0783^{*}$ & $-0,0218$ & 0,0254 & $-0,0367$ & $-0,0898 * \star$ & $-0,0079$ & $-0,0499$ & $-0,1708^{*}$ & $-0,1075^{*}$ & $-0,0964 *$ \\
\hline $\begin{array}{l}\text { Dendê } \\
\text { (cacho de } \\
\text { coco) }\end{array}$ & 0,0372 & - & 0,0181 & 0,0137 & $-0,0575$ & - & 0,0207 & 0,0047 & $0,0844 * * *$ & - & 0,0102 & 0,0197 \\
\hline Laranja & $-0,0109$ & $-0,1551$ * & $-0,1155^{*}$ & $-0,0704^{*}$ & $-0,0147$ & $-0,0488$ & $-0,0785^{\star *}$ & $-0,0242$ & $-0,1279 * *$ & $-0,2556^{*}$ & $-0,1326^{*}$ & $-0,1504^{*}$ \\
\hline $\begin{array}{c}\text { Extração } \\
\text { Vegetal }\end{array}$ & $0,2978 *$ & $0,3413^{*}$ & $0,2553 *$ & $0,2050 *$ & $0,2217 *$ & $0,2223^{*}$ & $0,2687^{*}$ & 0,1394 * & $0,3560 *$ & $0,4250^{*}$ & $0,2923 *$ & $0,3300 *$ \\
\hline Açaí (fruto) & $-0,0293$ & 0,0335 & 0,0201 & 0,0081 & - & $-0,0447$ & 0,0134 & $-0,0193$ & 0,0079 & $0,1011^{* *}$ & 0,0367 & 0,0570 ** \\
\hline Silvicultura & 0,1490 * & $0,1213^{*}$ & 0,0957 * & $0,0584^{*}$ & 0,0580 & $0,1555^{*}$ & $0,1502^{*}$ & $0,0436 * * *$ & $0,1890 *$ & 0,0755 & $-0,0230$ & $0,0441 * * *$ \\
\hline PIB2013 & $0,4017 *$ & $0,2573^{*}$ & $0,1586 *$ & $0,2605^{*}$ & $0,3907 *$ & $0,3012 *$ & $0,1280 *$ & 0,2774 * & $0,1415^{*}$ & 0,1291 * & $0,1219 *$ & 0,1404 * \\
\hline PIB2014 & $0,4057 *$ & $0,2622 *$ & $0,1656^{*}$ & $0,2649 *$ & $0,3909 *$ & $0,3006^{*}$ & $0,1422^{*}$ & 0,2817 * & 0,1497 * & $0,1352^{*}$ & $0,1212^{*}$ & $0,1432^{*}$ \\
\hline PIB2015 & $0,3957 *$ & 0,2637 * & 0,1721 * & $0,2663^{*}$ & $0,3812^{*}$ & $0,2964 *$ & $0,1439 *$ & 0,2791 * & $0,1479 *$ & $0,1421 *$ & $0,1326 *$ & $0,1507 *$ \\
\hline
\end{tabular}

Fonte: Resultados da pesquisa. * Valor significativo no nível de 1\% de significância. ** Valor significativo no nível de 5\% de significância. *** Valor significativo no nível de 10\% de significância.

A quantidade do rebanho bovino apresentou os maiores coeficientes de correlação positiva com o Programa ABC, exceto no Crédito Agrícola (APT A, CD e Total). Destaca-se que o rebanho bovino apresentou forte correlação com pastagens degradadas e em más condições, e observando o Crédito Total do Programa ABC, os coeficientes se situaram entre 0,58 e 0,78 , no nível de significância de $1 \%{ }^{6}$. Este resultado indica estreita relação da atividade de pecuária e a qualidade das pastagens. No entanto, observa-se que o rebanho bovino apresenta maior coeficiente de correlação com o crédito do Programa ABC, quando comparado às pastagens degradadas e em más condições.

\footnotetext{
${ }^{5}$ Os resultados da correlação das variáveis de PIB municipal com as pastagens degradadas e em más condições podem ser consultados no Apêndice $A$.

${ }^{6}$ Os resultados da correlação do rebanho bovino com as pastagens degradadas e em más condições podem ser consultados no Apêndice A.
} 
As culturas de açaí, cacau e dendê foram incluídas na análise de correlação devido à criação de linhas específicas no Programa ABC para estas culturas. Em geral, as correlações do crédito e as produções destas culturas não obtiveram significância estatística. Quando significativas, foram fracas, aproximando-se de uma associação nula.

Em diversos casos, os rebanhos de suínos e galináceos não apresentam resultados estatisticamente significativos. A baixa associação dos SPS propostos para estes rebanhos é uma hipótese para justificar este resultado. O Tratamento de Dejetos Animais (TDA) tem maior relação com rebanhos de suínos e galináceos, no entanto este subprograma representa parcela pequena dos investimentos. Os resultados significativos encontrados podem estar associados à concentração produtiva na agropecuária de maneira geral e não especificamente quanto aos rebanhos de suínos e galináceos.

Observando a correlação do crédito destinado a agricultura e pecuária, verifica-se que, na agricultura, existe menor aderência dos recursos do crédito com as características ambientais. Ao comparar as atividades, nos investimentos realizados na agricultura, há menor correlação com as pastagens degradadas e em más condições, e maior correlação com o PIB municipal e o valor da produção de lavouras temporárias, principalmente nas regiões de alta APT.

As análises até aqui desenvolvidas, portanto, sugerem que, conforme os recursos são destinados aos municípios de APT mais elevadas, existem maiores correlações com indicadores econômicos do que com as características ambientais. Estes resultados corroboram as análises apresentadas por Gianetti (2017), em avaliação do período de janeiro de 2013 a outubro de 2016. Destaca-se que, mais de um ano após a avaliação do autor, não foram realizadas alterações na execução e distribuição de recursos do Plano e Programa ABC capazes de influenciar o resultado total do período analisado.

A partir da análise das características do Programa ABC acima mencionadas, é possível identificar duas deficiências principais na execução do programa: a distribuição de recursos entre as linhas de financiamento do Programa ABC e a sua alocação regional.

Inicialmente, a constatação da contratação efetiva de apenas quatro do total de 10 linhas do Programa ABC é uma deficiência que demanda atenção. Em alguns casos, como na adoção da tecnologia de fixação biológica de nitrogênio, pode não haver necessidade de contratação de crédito. Além disso, outras linhas beneficiam culturas que apresentam baixa produção e representatividade no território nacional. Outros entraves são ainda retratados na literatura, como a burocracia, a falta de assistência técnica, entre outros (Observatório ABC, 2017a).

Uma possibilidade para contornar a concentração entre os subprogramas consiste na reestruturação das alíneas do Programa ABC. Por exemplo, em um sistema de iLPF, o produtor pode aderir ao sistema de plantio direto para a lavoura, incorporando a fixação biológica de nitrogênio, realizando a implementação de gêneros florestais e valendo-se deste processo para recuperar as pastagens degradadas. Em um caso, como no exemplo citado, as divisões delimitadas das linhas do Programa perdem o sentido. Ou seja, a sobreposição das técnicas dos diversos SPS dificulta a análise de implementação do Plano e Programa ABC.

Um dos principais indicadores de resultado apresentado pelo Plano $A B C$ é a área de utilização dos SPS, conforme as metas mencionadas anteriormente. No entanto, caso avaliado o Programa $A B C$ de maneira geral, o critério de área pode não ser a característica mais adequada para mensurar a efetividade do ABC. Metodologias para o cálculo de mitigação de emissões de GEE poderiam ser utilizadas, salientando as diferenças das variações dos SPS e das características edafoclimáticas das regiões brasileiras nos impactos de mitigação de GEE. Pellegrino et al. (2015) também evidenciam a necessidade de fatores de emissões de GEE específicos ao ABC, assim como o acompanhamento da eficiência econômica e técnica dos projetos financiados.

O segundo ponto diz respeito à ineficiência da alocação dos recursos entre as regiões brasileiras. Neste caso, os dados mostram que as regiões que deveriam ser prioritárias recebem baixo volume de recursos. Além disto, existem deficiências na aplicação dos recursos de acordo com a aptidão agrícola (APT). Diante das considerações da literatura citada sobre a necessidade de investimentos nas regiões Norte e Nordeste, e até mesmo na região Centro-Oeste, a APT pode ser utilizada para verificação mais específica das características ambientais das áreas de aplicação dos investimentos do ABC. Esta mensuração poderia ser 
realizada pela delimitação da área de implantação dos investimentos e conferência da propriedade através da base de dados de APT. A ferramenta para tal avaliação existe, uma vez que o Cadastro Ambiental Rural (CAR) inclui a delimitação da área da propriedade por meio de imagens de satélite.

As sugestões expostas indicam a necessidade de criação de um sistema que elenque, explicitamente, as áreas prioritárias para implementação do Programa ABC. Este sistema gerará possibilidades para a diferenciação de benefícios e subsídios de acordo com as reais necessidades da área de aplicação dos investimentos do Programa, o que poderá resultar em melhor distribuição de recursos para alcançar os objetivos traçados. Conforme discutido anteriormente, o território nacional é heterogêneo em diversos aspectos, sendo os riscos, os regimes climáticos, o conhecimento técnico e o desenvolvimento econômico, alguns deles. Estas características influenciam diretamente na aplicabilidade do Plano e Programa ABC.

\section{Considerações Finais}

Os resultados mostraram que a execução e a distribuição de recursos do Programa $A B C$ têm concentração regional e nos sistemas de RPD, SPD, FLP e iLPF. Aparentemente, as dificuldades envolvidas nos subprogramas de FBN, TDA e ARA têm limitado a adesão destas tecnologias a patamares extremamente baixos. Como reavaliação do Plano e Programa ABC, o caráter não exclusivo das linhas de financiamento poderia auxiliar a ampliação da contratação dos empréstimos.

A alocação dos recursos de acordo com as características edafoclimáticas de cada região também apresenta deficiências. As dificuldades com a implementação das tecnologias ocorrem, sobretudo, nas regiões em que os recursos deveriam ser aplicados, como nos municípios de baixa APT. Critérios para definir explicitamente as regiões prioritárias para o Programa ABC devem ser criados. Variáveis, como a APT, podem ser combinadas com o CAR, para gerar informações que permitam conceder recursos em condições diferenciadas, conforme as características ambientais.

A maior correlação observada do crédito concedido pelo Programa $A B C$ com o rebanho bovino do que com as pastagens degradadas, bem como a maior correlação da APT do município com o crédito destinado à produção de lavouras temporárias e com o PIB municipal, mostram que as variáveis econômicas e da produção agropecuária possuem maior relação com a contratação do Programa $A B C$ do que as características ambientais. Estas deficiências ampliam-se quando os empréstimos são destinados à atividade agrícola.

Existem algumas limitações quanto às variáveis utilizadas neste trabalho. A APT possui restrições quanto à precisão da classificação devido à necessidade de utilizar a APT predominante no município para caracterizá-los. Devido à falta de informações sobre a mitigação de GEE ou a área abrangida, não é possível realizar conferência precisa do realizado com as metas originais do Plano ABC. Também não foi considerada a possibilidade de adoção dos Sistemas de Produção Sustentáveis sem o crédito do $A B C$, principalmente devido às dificuldades na obtenção de dados. Finalmente, além das possibilidades de novos estudos através de melhorias na base de dados, podem ser realizadas delimitações, estabelecendo regiões, estados e até mesmo municípios específicos, de modo a proporcionar uma revisão do Programa ABC de acordo com as necessidades destes locais, inclusive com características institucionais.

\section{Agradecimentos}

O presente trabalho foi realizado com apoio da Coordenação de Aperfeiçoamento de Pessoal de Nível Superior - Brasil (CAPES) - Código de Financiamento 001.

\section{Referências}

Assad, E. D. (2015). Agricultura de baixa emissão de carbono: a evolução de um novo paradigma Eduardo de Morais Pavão (38 p.). Observatório ABC.

Banco Central do Brasil - BACEN. (2016). Crédito rural: programa para redução da emissão de gases de efeito estufa na Agricultura (Programa $A B C$ ). Brasília. 
Banco Central do Brasil. (2018). Matriz de dados do crédito rural. Brasília. Recuperado em 1 de março de 2018, de http://www.bcb.gov.br/pt-br/\#!/c/MICRRURAL/

Barros, A. M. (2017). Avaliação do uso estratégico das áreas prioritárias do Programa ABC (35 p). Observatório ABC.

Brasil. Ministério da Agricultura, Pecuária e Abastecimento - MAPA. (2012). Plano setorial de mitigação e adaptação às mudanças climáticas para consolidação da economia de baixa emissão de carbono na agricultura (173 p.). Brasília: MAPA/ACS.

Brasil. (2015). Pretendida contribuição nacionalmente determinada. Brasília. Recuperado em 17 de julho de 2017, de http://www.itamaraty.gov.br/images/ed_desenvsust/BRASIL-iNDC-portugues.pdf

Brasil. (2018). Política Nacional sobre Mudança do Clima. Brasília. Recuperado em 17 de julho de 2017, de https://www.mma.gov.br/clima/politica-nacional-sobre-mudanca-do-clima

Chen, P. Y., \& Popovich, P. M. (2002). Correlation: parametric and nonparametric measures (Sage University Papers Series on Quantitative Applications in the Social Sciences). Thousand Oaks: Sage.

Dias Filho, M. B. (2014). Diagnóstico das pastagens no Brasil (36 p.). Embrapa Amazônia Oriental.

Empresa Brasileira de Pesquisa Agropecuária - EMBRAPA. (2017). Fixação biológica de nitrogênio: sobre o tema. Embrapa. Recuperado em 15 de setembro de 2017, de https://www.embrapa.br/temafixacao-biologica-de-nitrogenio/nota-tecnica

Ferreira Filho, J. B. S., \& Horridge, M. (2017). Biome composition in deforestation deterrence and GHG emissions in Brazil (Centre of Policy Studies/IMPACT Centre Working Papers, 14 p.). Victoria University.

Fornazier, A., \& Vieira Filho, J. E. R. (2012). Heterogeneidade estrutural no setor agropecuário brasileiro: evidências a partir do censo agropecuário de 2006 (34 p.). Brasília: Instituto de Pesquisa Econômica Aplicada.

Gianetti, G. W. (2017). O Plano e Programa ABC: uma avaliação da execução e distribuição dos recursos (Dissertação de mestrado). Escola Superior de Agricultura "Luiz de Queiroz", Universidade de São Paulo, Piracicaba.

Hungria, M., Mendes, I. C., \& Mercante, F. M. (2013). A fixação biológica do nitrogênio como tecnologia de baixa emissão de carbono para as culturas do feijoeiro e da soja (24 p.). Londrina: Embrapa Soja.

Instituto Brasileiro de Geografia e Estatística - IBGE. (2018a). Censos agropecuários 2006 e 2017. Recuperado em 15 de outubro de 2018, de http://www.ibge.gov.br

Instituto Brasileiro de Geografia e Estatística - IBGE. (2018b). Produção agrícola municipal. Recuperado em 24 de fevereiro de 2018, de https://sidra.ibge.gov.br

Instituto Brasileiro de Geografia e Estatística - IBGE. (2018c). Pesquisa pecuária municipal. Recuperado em 24 de fevereiro de 2018, de https://sidra.ibge.gov.br

Instituto Brasileiro de Geografia e Estatística - IBGE. (2018d). Produção da extração vegetal e da silvicultura. Recuperado em 24 de fevereiro de 2018, de https://sidra.ibge.gov.br

Instituto Brasileiro de Geografia e Estatística - IBGE. (2018e). Produto Interno Bruto dos municípios. Recuperado em 24 de fevereiro de 2018, de https://sidra.ibge.gov,br/pesquisa/pib-munic/tabelas

Kunz, A., Higarashi, M. M., \& Oliveira, P. A. (2005). Tecnologias de manejo e tratamento de dejetos de suínos estudadas no Brasil. Cadernos de Ciência \& Tecnologia, 22(3), 651-665.

Larcher, T. P. A. O. (2016). Construção de um modelo lógico do Plano ABC (Agricultura de Baixa Emissão de Carbono) como uma proposta de avaliação (Dissertação de mestrado). Universidade de Brasília, Brasília.

Leal, B. P. (2016). Programa ABC: uma análise para o período de 2011 a 2014 (Dissertação de mestrado). Fundação Getúlio Vargas, São Paulo.

Observatório ABC. (2015). Propostas para revisão do Plano ABC. Recuperado em 13 de janeiro de 2017, de http://observatorioabc.com.br/publicacoes/

Observatório ABC. (2017a). Análise dos recursos do Programa ABC Safra 2016/17. Recuperado em 1 de janeiro de 2017, de http://observatorioabc.com.br/publicacoes/

Observatório ABC. (2017b). Impactos econômicos e ambientais do Plano ABC. Recuperado em 13 de janeiro de 2017, de http://observatorioabc.com.br/publicacoes/

Observatório do Clima. (2014). Análise da evolução das emissões de GEE no Brasil (1990-2012) (21p.). São Paulo. 
Pellegrino, G. Q., Rodrigues, R. A. R., Oliveira, A. F., Assad, E. D., \& Cordeiro, L. A. M. (2015). Proposal for the construction of a greenhouse gas emissions 61 monitoring system for the ABC Plan: sectoral plan for mitigation and adaptation to climate change for the consolidation of a low carbon agriculture economy. In C. A. Zolin \& R. A. R. Rodrigues (Eds.), Impact of climate change on water resources in agriculture (1st ed., Vol. 1, pp. 61-84). Boca Raton: CRC Press.

Sistema de Registro Nacional de Emissões - SIRENE. (2018). Emissões em dióxido de carbono equivalente por setor. Brasília. Recuperado em 1 de março de 2018, de http://sirene.mcti.gov.br/web/guest/emissoes-em-co2-e-por-setor

Sparovek, G. (Ed.). (2015). Avaliação da implementação do Plano Setorial de Mitigação e de Adaptação às Mudanças Climáticas para a Consolidação de uma Economia de Baixa Emissão de Carbono na Agricultura-PLANO ABC (Projeto de Cooperação Técnica IICA/BRA/02/2015). Piracicaba.

Sparovek, G., Barretto, A., Klug, I., Papp, L., \& Lino, J. (2011). A revisão do Código Florestal brasileiro. Novos Estudos, 89(89), 111-135.

Submetido: $15 /$ Nov./2018

Aceito: 12/Fev./2020

Classificação JEL: Q10; Q18; Q28. 
Apêndice A. Correlação de Spearman do PIB e rebanho bovino com as pastagens degradadas e em más condições, por aptidão agrícola

\begin{tabular}{|c|c|c|c|c|c|c|c|c|}
\hline \multirow{2}{*}{ Correlação } & \multicolumn{4}{|c|}{ Pastagem Degradada 2006} & \multicolumn{4}{|c|}{ Pastagem em Más Condições 2017} \\
\hline & Apt. A & Apt. B & Apt. CD & Total & Apt. A & Apt. B & Apt. CD & Total \\
\hline PIB 2013 & $0,1538 *$ & $0,1150 *$ & $0,1316 *$ & $0,1198 *$ & $0,1620^{*}$ & 0,0348 & 0,0192 & 0,0134 \\
\hline PIB 2014 & $0,1598 *$ & $0,1278^{*}$ & $0,1419 *$ & $0,1260 *$ & $0,1683^{*}$ & 0,0420 & 0,0247 & 0,0216 \\
\hline PIB 2015 & $0,1539 *$ & $0,1346 *$ & $0,1457 *$ & $0,1309 *$ & $0,1632^{*}$ & 0,0537 & 0,0292 & $\underset{*}{0,0288^{* *}}$ \\
\hline Rebanho Bovino & $0,7814^{*}$ & 0,7441 * & $0,6876 *$ & $0,7235^{\star}$ & $0,7563^{*}$ & $0,6434 *$ & $0,5785^{*}$ & $0,5758^{*}$ \\
\hline
\end{tabular}

Fonte: Resultados da pesquisa. * Valor significativo no nível de $1 \%$ de significância. ** Valor significativo no nível de $5 \%$ de significância. *** Valor significativo no nível de 10\% de significância. 